\title{
¿NAHUATLISMOS PEDINCHE, LLORICHE, ETC., O CASOS DE FONOSIMBOLISMO?
}

\section{NAHUATLISMS PEDINCHE, LLORICHE, ETC., OR CASES OF PHONOSYMBOLISM?}

\author{
LUIS FERNANDO LARA \\ El Colegio de México \\ El Colegio Nacional \\ lara@colmex.mx
}

\begin{abstract}
Resumen: Se considera la hipótesis propuesta por Antonio Alatorre de que voces como pedinche, lloriche, etc., son híbridos de raíz española y sufijo nahua, frente a la de Juan M. Lope Blanch, de que se trata de formaciones "caprichosas" del español de México. Tras una revisión de los vocablos listados en los diccionarios con las terminaciones -che, $-i(n)$ che, se propone la tesis de que se trata de casos de fonosimbolismo.

Palabras clave: pedinche; lloriche, nahuatlismos; fonosimbolismo; español de México.
\end{abstract}

Abstract: This article discusses Antonio Alatorre's hypothesis that words such as pedinche, lloriche, etc. are hybrids rooted in Spanish but with a Nahuatl suffix, whilst Juan M. Lope Blanch, on the other hand, sees these words as whimsical formations in Mexican Spanish. After reviewing the words listed with -che, $i(n)$ che endings in dictionaries, we suggest that they are all examples of phonosymbolism.

Keywords: pedinche; lloriche, nahuatlisms; phonosymbolism; Mexican Spanish.

Recepción: 1 de septiembre de 2017; aceptación: 23 de noviembre de 2017.

D.R. ( 2019. Nueva Revista de Filología Hispánica

Licencia Creative Commons Attribution-NonCommercial (CC BY-NC) 4.0 International 
En el Homenaje a Antonio Alatorre que publicó la Nueva Revista de Filología Hispánica (t. 40, 1992, pp. 623-636), Juan M. Lope Blanch dio a conocer sus argumentos acerca de si varios vocablos terminados en -che, -i(n)che, como pedinche, lloriche, metiche, etc., comunes en Jalisco, podrían ser -como le había comentado Antonio Alatorre oralmente-, híbridos formados por una raíz española y un sufijo -che, -i(n)che, derivado del reverencial o afectivo nahua -tzin o -tzintli. Nueve años más tarde, en "Sobre americanismos en general y mexicanismos en especial", del tomo 49, 1 (2001, pp. 1-51) de la misma revista, Antonio Alatorre dio a conocer su hipótesis de que

lloriche y compañía constituyen un grupo coherente, así en lo semántico (designación de "vicios" infantiles) como en lo morfológico: radical español (llor-, etc.) y sufijo náhuatl (-tzin), con un -i- que sirve de enlace. A lo cual hay que agregar que, según toda verosimilitud, su lugar de origen no fue México Tenochtitlán, sino el Occidente, en especial Jalisco, la zona en que se hablaba lo que Dávila Garibi llama "idioma coca" (p. 7) ${ }^{1}$.

La explicación de Alatorre consiste en atribuir la formación de esos supuestos híbridos o construcciones mestizas de español y náhuatl a que

en casa de los españoles (y criollos) había una india destinada a la crianza de los niños... Estas mujeres hablan ya español, pero "piensan" aún en náhuatl y, como se encariñan con el condenado güerito, aceptan de buena gana la lata que da y le dicen que es un lloritzin, un caguitzin, etc., empleando el sufijo náhuatl -tzin, denotador no sólo de respeto (Malintzin, huehuetzin 'venerable anciano'), sino también de cariño y ternura (p. 6).

La hipótesis de Alatorre es muy atractiva, tanto por su claridad: raíz española y sufijo reverencial o afectivo nahua, como por la manera, tan suya, tan plástica, con que la expone. La réplica adelantada de Lope Blanch parece "españolista": revisa un grupo de vocablos con esas dos terminaciones y lo contrasta con la información etimológica disponible en el Diccionario crítico etimológico castellano e hispánico de Joan Corominas y José Antonio Pascual (1991), junto con información procedente, sobre todo del Diccionario de mejicanismos de Francisco J. Santamaría (1959), que lo llevan a poner en cuestión la hipótesis de Alatorre. Lope Blanch señala:

${ }^{1} \mathrm{Al}$ razonamiento de Alatorre se puede agregar lo que afirma SwADESH (1966); al hablar de algunas alternancias funcionales en la formación de la palabra náhuatl, señala que "los derivados nominales muchas veces manifiestan la $i$ " (p. 11). Alatorre se refiere a Dávila Garibi 1935. 
Nos hallamos... ante dos interpretaciones diferentes de la terminación -che. Según la primera, esa terminación -che (¿` -i(n)che?) tiene origen indoamericano, ya sea que proceda del sufijo nahua -tzin [ŝin], ya se trate de una desinencia propia de la lengua coca. Según la segunda, dicha terminación sería una desinencia caprichosa independiente de todo morfema amerindio (p. 624).

Para poder sostener el argumento central de Alatorre son necesarios: a) datos de la variedad nahua que puede haberse hablado en el Occidente de México, especialmente en el actual Estado de Jalisco, o de Nayarit -como se verá en seguida- o, en todo caso, de la lengua coca; $b$ ) documentos que demuestren los procesos de formación morfológica de vocablos híbridos de español y náhuatl, particularmente en la formación de adjetivos atributivos.

Las obras de que puede uno disponer actualmente no permiten reconocer, en el náhuatl registrado de Jalisco, la formación de adjetivos nahuas de esa clase con la terminación reverencial o afectiva -tzin para los nombres propios o poseídos, y -tzintli para los sustantivos no poseídos ${ }^{2}$. Tratándose de sustantivos, el caso más evidente de formación de un híbrido español/nahua es el de Malintzin ${ }^{3}$, nombre que daban los nahuas a Hernán Cortés debido al papel de su mujer y traductora, Marina ${ }^{4}$-cuyo nombre originario se desconoce-, pero llamada Malia o Malina por los nahuas. La inexistencia de una distinción fonológica nahua entre $/ 1 /: / \mathrm{r} /{ }^{5}$ llevó a la formación de Marina $>$ Malina, y de allí al reverencial Malintzin, en español mexicano, Malinche. En náhuatl, muchos sustantivos reciben el sufijo -tzin, por ejemplo, huehuenche < huehue 'anciano' + n-tzin 'anciano venerable', como señala Alatorre basándose en Molina (2013 [1555]); nanche ${ }^{6}$

2 Cortés y Zedeño 1967 [1765]; Guerra 1900 [1692]. Aunque hay que notar la cita de Lope Blanch (p. 626) del Arte de la lengua mexicana, de Alonso DE MoliNA (1576): "a los nombres propios, Substantivos y Adjectivos, que significan cosas animadas, o inanimadas se les añade algunas veces tzin, o tzintli. Y esto acaece, para denotar buena criança, cortesía, o reverencia. Exemplo veventzi[n], viejo honrado. Ytem para denotar afabilidad y mansedumbre. Exemplo, ychpuchtzintli, bendita donzella. Item para denotar compassión y piedad. Exem. cocoxcatzintli, enfermo al qual tenemos voluntad y nos compadecemos dél” (p. 12r. y v.).

3 Aunque el origen del nombre no resulta muy claro para Alfredo López Austin, a quien, junto con Rodrigo Martínez Baracs, agradezco sus observaciones y correcciones a este artículo.

4 Así la llama Bernal díaz del Castillo en su Historia verdadera de la conquista de la Nueva España (cap. 36). Véase la ed. de 2014 a cargo de Guillermo Serés.

5 Véase LARa 2008, n. 89.

6 López Austin pone en duda esa etimología. Nanche: “(Byrsonima crassifolia) Árbol o arbusto de la familia de las malpigiáceas de distintas variedades que da este fruto. Alcanza hasta $10 \mathrm{~m}$ de altura, tiene las hojas anchamente ovales, de color verde brillante en el haz y opaco en el envés; sus flores, de color amarillo rojizo, crecen en 
$<$ nantli 'madre' + tzin reverencial; cacahuananche ${ }^{7}<$ cacáhuatl 'cacao' + nantli 'madre' + tzin reverencial; tencuache 'labio leporino' < tencua 'labio comido' < tentli 'labio' + cualo 'comido' + tzin ${ }^{8}$; teopiscachi o teopizcache < teopixqui 'guardián de Dios', 'sacerdote católico' < téotl 'dios' + pixqui 'guardián' + tzin reverencial; tlalcocolchi $<$ tlalcocoltzin (cierto arbusto $)<$ tlalli 'tierra' + cocóltic 'retorcido' + tzintli $i^{9}$;oloach $e^{10}<$ toloa 'inclinar la cabeza o cabecear por efecto del sueño' ${ }^{11}+t z i n$ reverencial o diminutivo. Salvo en casos como huehuenche o teopiscachi, en los que el valor reverencial de -tzin parece claro, le asalta a uno la duda de si, cuando se trata de nombres de plantas, interviene el mismo morfema constructor de voces reverenciales o si éste no tenía o tiene en náhuatl otro valor semántico. Los siguientes nahuatlismos terminados en -che o -chi no son casos de raíz + tzin: cuatatachi< cuáhuitl 'árbol' + tlatlatzini 'que truena' (Cabrera 1974 y Molina 2013 [1555]); cuiche ¿o cuichtli 'hollín' (Cabrera y Molina)?; cuitlacoche o

racimos terminales. Su corteza se emplea en medicina tradicional como astringente, para combatir la diabetes y las infecciones intestinales o de la boca. Se cultiva en regiones de clima cálido” (DEM, s.v.).

7 Cacahuananche: "(También cacahuanance, cacahuananche, cacahuanantzin, cacahoanance o cacahoananchi) (Gliricidia sepium) Árbol silvestre de la familia de las leguminosas que alcanza hasta los $15 \mathrm{~m}$ de altura; sus hojas y la corteza, con espinas, son venenosas; sus flores son de color rosado pálido y sus frutos tienen forma de vaina; se utiliza como forraje y para dar sombra a los cacaotales; coatante, cocohite; madre del cacao, madre chontal, madre mansa, madre brava" (DEM, s.v.).

8 Alonso de Molina, en su Vocabulario en lengua mexicana-castellana (1555), no incluye una forma que pudiera haber evolucionado a tencuache, explicado por CABRERA en su Diccionario de aztequismos (1974) a partir de tencua 'de labio leporino', de tencuallo ‘labio comido' y reproducido más o menos de la misma forma por RoBELo 1940. Para CABrera, tencuache es "diminutivo de tencua, con la desinencia tzin". En Molina se encuentra una interesante familia de expresiones formadas por tencua-y tenqua-, cuyo campo léxico refiere a la boca, los labios, la lengua y cualquier borde. Bajo tentli, Molına glosa: "los labrios, o el borde, o orilla de alguna cosa" (véase la ed. de 2013).

9 Molina (2013 [1555]): tzintli ‘el ojo del salvonor'. CABrera (1974) no identifica la planta, sólo señala "Planta cuya raíz y hojas se suponen ser antivenéreas".

10 Toloache: "Planta herbácea de la familia de las solanáceas que mide entre 60 $\mathrm{cm}$ a $1 \mathrm{~m}$ de altura; está cubierta de pelo fino y suave; sus hojas son ovales y agudas, de 10 a $20 \mathrm{~cm}$; sus flores son monopétalas, tubulosas, de color blanco, purpúreo o violáceo y su fruto es globoso y espinoso, como la Datura innoxia, la Datura meteloides y la Datura stramonium; se la conoce por sus efectos narcóticos, alucinógenos y espasmódicos; es muy venenosa" (DEM, s.v.).

11 López Austin piensa que toloa se refiere a la posición de las flores hacia abajo. 
huitlacoche ${ }^{12}<$ cuítlatl 'mierda' + cochi 'dormir' ${ }^{13}$; chiche o chichi $^{14}$; huisache o huizache ${ }^{15}<$ huixachi 'árbol espinoso' < huitztli 'espinas' + ixachi 'en cantidad'; huistlacuachi 'puerco espín' < huitztli 'espina' + tlacuatzin 'tlacuache'; mapache $e^{16}<$ mapachoa 'apretar algo con la mano' $<$ maitl 'mano' + pachoa 'apretar la barriga'17; pachiche $e^{18}<$ patzactic 'trigo o maíz añublado' (Cabrera, basado en Molina) ${ }^{19}$-y también bachiche o bachicha 'colilla de un cigarrillo', de la misma etimología, según Cabrera ${ }^{20}-$; tepache $e^{21}<$ tepachoa 'machacar algo con una piedra';

12 Cuitlacoche: "(Ustilago maydis) Hongo parásito que invade las mazorcas tiernas del maíz; aparece a manera de grandes tumores de un blanco grisáceo que, cuando maduran, revientan y liberan infinidad de esporas negras; es comestible, cocido o guisado; huitlacoche: tacos de cuitlacoche, arroz con cuitlacoche" (DEM, s.v.).

13 Según Cabrera 1974 y Montemayor 2007, pero Molina 2013 [1555]: cuitlacochtli 'maýz o trigo añublado'.

14 Chichi: "Cada uno de los pechos de la mujer o de las tetas de las hembras de los animales; chiche: bonitas chichis, enseñar las chichis, «Le estaba dando la chichi al niño»" (DEM, s.v.). Su origen es chichihualli. En maya y en el español de Yucatán, chichi significa 'miga de pan'; es un homónimo de la voz nahua.

15 Huizache. "(Acacia farnesiana) Árbol o arbusto de la familia de las leguminosas, de hasta $9 \mathrm{~m}$ de altura, de ramas espinosas, corteza delgada, vainas de color morado negruzco y flores amarillas muy olorosas. De su vaina se extrae una sustancia llamada tanino, que sirve para hacer tinta negra; el tronco produce un tipo de goma; de sus flores se obtiene la esencia de acacia que se utiliza en perfumería, y sus hojas se usan como alimento para el ganado" (DEM, s.v.).

16 Mapache. "(Procyon lotor) Mamífero carnívoro de cuerpo ancho, patas cortas y robustas con cinco dedos, cabeza ancha, de hocico puntiagudo y orejas cortas; alrededor de los ojos tiene una mancha negra, a manera de antifaz; mide de 40 a $60 \mathrm{~cm}$ de largo; su piel es gris o amarillenta, combinada con negro, y su cola tiene varios anillos blancos y negros; sus patas delanteras son prensiles; lava sus alimentos antes de comerlos. Habita cerca de ríos y lagos y se alimenta de crustáceos, peces, roedores y frutas" (DEM, s.v.). En este caso y en el de tlacuache, López Austin señala que la razón del reverencial puede deberse a su parecido con los humanos, en cuanto que sus extremidades delanteras oponen el dedo pulgar a los otros.

17 Molina 2013 [1555]: pachoa 'abajarse inclinando el cuerpo o apretarse la barriga'. Para López Austin no es correcta la etimología que propone.

18 Pachiche: "1 Tratándose de un fruto o de una flor, que está arrugado, marchito, pasado, sin jugo o poco desarrollado: «Yo comía las naranjas pachiches, de esas que se caen y les pega el sol durante el día», mangos pachiches. 2 Tratándose de personas o de algunas cosas, que está viejo o arrugado" (DEM, s.v.).

19 En este caso se nota la formación del adjetivo nahua con el sufijo -tic. Véase más abajo.

20 Según López Austin, las hipótesis etimológicas que proponen RoBELo 1940, CABRERA 1974 y MONTEMAYOR 2007 para bachiche, bachicha, tepache, tlalcocochi, macuache, taniche, chilinche, conchiche, sagabiche, coliche, cortichi, zumbiche y chamaco son muy probablemente erróneas.

21 Tepache: "Bebida refrescante que se prepara con el jugo fermentado de la piña o de otras frutas y se endulza con piloncillo o azúcar” (DEM, s.v.). 
tlacuache ${ }^{22}$ 'bocadillo sabroso' < tlacua 'comer'23; tololoch $e^{24}<$ tololóntic, reduplicativo de tolóntic 'cosa redonda', otro adjetivo con sufijo -tic; totatiche < totatlichan 'casa paterna' < to 'nuestro' + tali 'padre' + chantli 'casa'. Respecto a macuache 'pobre', al que Robelo (1940), Dávila Garibi (1935) y Santamaría (1959) le atribuyen como etimología el nahua macehua 'sufrir, ser despreciable', es todavía más difícil adjudicarle un origen nahua.

En náhuatl, según Swadesh (1966), los "sustantivos descriptivos (nuestros adjetivos), son generalmente derivados de nombres concretos y tienen principalmente las terminaciones -c, -ti-c, -to-c parecido a" (p. 30). Los vocablos que dieron lugar a la hipótesis de Alatorre son todos adjetivos: caguiche, habliche, lloriche, lambiche, metiche, cantaliche, peguiche, trampiche, además pedi(n)che, güerinche. Parece descartar jolinche 'rabón, rabicorto' y barbinche 'lampiño', “que naturalmente no se dicen de los niños chiquitos", así como las variantes jolincho y rabincho; pero quizá se podría agregar pepenche 'consentido, chiqueado, dependiente', por su significado y por su uso en las mismas regiones ${ }^{25}$. Puede

22 Tlacuache: "Animal mamífero del orden de los marsupiales, por lo general de color gris, que llega a medir hasta $45 \mathrm{~cm}$ de largo sin considerar la cola. Tiene el hocico puntiagudo, las orejas cortas y redondas, las patas cortas en relación con el cuerpo y una cola larga que le sirve para colgarse, para coger cosas y transportarlas. La hembra tiene una bolsa en la que lleva a sus crías mientras terminan de desarrollarse. Se alimenta de carroña, frutos, verduras, y de huevos y polluelos de aves, por lo que es considerado plaga cuando habita cerca de los gallineros; es un animal de hábitos nocturnos y tiene la peculiaridad de fingirse muerto cuando se lo atrapa. En algunas regiones se caza y se consume como alimento" (DEM, s.v.).

${ }^{23}$ Según Cabrera (1974), Montemayor no ofrece una etimología y Molina no registra ni el animal, ni voz parecida. SWADESH (1966) descompone tlacuatzin: tla 'cosa' + cua 'come' + tzin, diminutivo. López Austin, en los apéndices de su libro Los mitos del tlacuache (1996), cita de Gaspar de Covarrubias (1986 [1580], pp. 150-151): "Críanse [en los montes de Texcaltitlan] otros animalejos que se dicen tlaquatzin, que significa 'comedor' porque come gallinas” (p. 462). En este vocablo -tzin podría ser reverencial, dado el papel del tlacuache en la mitología nahua, pues, dice López Austin, "Nuestro personaje es, por excelencia, el comedor. Su nombre náhuatl, tlacuatzin o tlácuatl, deriva del verbo cua, 'comer'. Lo que come es, por supuesto, el alimento por excelencia, el maíz, con el que comparte naturaleza. Entre los mayas esto es más claro, puesto que la palabra och significa 'tlacuache'; pero también quiere decir 'sustento o comida', y en otras lenguas mayenses la referencia al maíz se hace precisa. En kekchí, por ejemplo, och significa 'jilote tierno'. Och, por tanto, es una calidad. Es la calidad de la que participan el tlacuache, el maíz y esa luz roja que, según dicen los tzotziles, precede al alba" (p. 304). Es decir, tlacuache no significa 'bocadillo sabroso'.

24 Tololoche: "Contrabajo, particularmente el que forma parte de la orquesta de mariachis" (DEM, s.v.).

${ }^{25}$ Notablemente, este adjetivo, de forma similar a los que aduce AlatorRe, no recibió atención ni por parte suya ni de Cabrera 1974 y Montemayor 2007; ni Molina 2013 [1555] ni CoRominas 1991 ofrecen alguna forma que lo explique. El vocablo se usa en las mismas regiones de Jalisco y el Noroeste. Véase el artículo correspondiente en el DEM. De ahí se vislumbra un rasgo semántico profundo de 
uno preguntarse, en consecuencia, si las pilmamas nahuas de los niños españoles y criollos al llamarlos así los significaban adhiriendo a la raíz española -tic, de valor adjetivo, a los que después se añadiera la partícula afectiva, mediante algún proceso morfofonológico característico del náhuatl. También puede uno preguntarse cuáles podrían haber sido los radicales españoles de los deverbales sobre los que se formaron los híbridos, pues llorón y cagón son diferentes de hablador, cantador (?), pegón o pegador, etc. Igualmente puede uno preguntarse si la morfología nahua introduce automáticamente, no en ocasiones, esa - $i$ - de enlace. Quedan, por lo tanto, muchas preguntas sin respuesta.

No forman parte de los vocablos considerados por Alatorre cuatachey cuatacho 'gemelo'26; joronche ‘jorobado'; timboroche 'timbón, barrigón'; culimiche 'mísero, cicatero, de poco valor'; culichi o culiche, el gentilicio de los habitantes de Culiacán; pelangoche 'pelado, persona de mala educación'. Se podrían agregar pinichey jurifiche ‘diablo', que Lope Blanch dice haber escuchado en alguna parte, y taniche 'tienducha', registrado por Peter Boyd-Bowman en su Habla de Guanajuato (1960), además de "chilinche, conchiche, sagabiche, coliche, copiche ${ }^{27}$, cortinchi..., droguiche (quizá de droga 'deuda')..., sopiche..., zumbiche”, que Alatorre encuentra registrados en el Índice de mexicanismos de la Academia Mexicana de la Lengua (p. 7, n. 12) ${ }^{28}$. Huarache/guarache, tambache 'bulto grande' y tagüinchi 'luciérnaga', según el Diccionario de colimotismos, se atribuyen al purépecha.

José Ignacio Dávila Garibi, en cambio, había propuesto desde 1935 la existencia de una lengua llamada coca en Jalisco, basado en documentos históricos que, aun cuando la mencionan, ni la describen ni ofrecen pruebas de ella; entre otros, la Geografía de las lenguas y carta etnográfica de México de Manuel Orozco y Berra. Según don José Ignacio (1945), esa lengua se habrá hablado hasta "las postrimerías del siglo Xıx" (p. 24) en Tonalá y en Cocula, Jalisco. Dávila Garibi (1945, pp. 57-64) insiste en que se recogieron varios vocablos de coca en documentos del siglo xvi y que hay cierto parentesco entre esta lengua y la cahita, por lo que propone que el coca forma parte de un grupo genealógico taracahita ${ }^{29}$. A la vez, no deja de señalar, con

'dependiente'. En "El baile de los pepenches" de José Clemente Orozco, también jalisciense, en que aparece una pareja "bien vestida" bailando, es difícil saber a qué se refería.

${ }^{26}$ Lope Blanch (p. 630) lo agrega a la lista que ofrece Alatorre.

27 Cabrera 1974: cópitl 'luciérnaga' + tzin, diminutivo, nombre de ese insecto en una región bien delimitada del Noroeste, como lo atestigua copechi en el Atlas lingüístico de México, s.v. luciérnaga.

28 Todos ellos procedentes de los glosarios de los diez tomos de las Relaciones geográficas del siglo XVI, editadas por RENÉ ACUÑa en 1982-1988.

29 CAmpbell (1997, pp. 133-136) lista el coca entre esas lenguas del tronco yuto-azteca, quizá repitiendo los datos de Orozco y BERRA 1864, pues no parece haber otros más recientes y mejor sustentados empíricamente. 
insistencia (passim), la profunda "nahuatlización" de la región desde el siglo Xvi para eludir la multitud de lenguas regionales que dificultaban la conquista y la evangelización. Alatorre (p. 5, n. 5) supone al pasar que la lengua coca no sería otra cosa que un náhuatl jalisciense. En tanto no se puedan verificar las afirmaciones de Dávila Garibi, tampoco es posible suponer que haya habido un sufijo coca estimativo, afectivo o diminutivo, que hubiera dado lugar al -che o $-i(n)$ che $e^{30}$. ¿Podría tratarse de otra lengua, como el cora?

El Diccionario inverso de la lengua española, de Ignacio Bosque, acumula 185 vocablos con terminación -che. Entre ellos aparecen los siguientes nahuatlismos: mapache, tepache, tlacuache, además, huarache o guarache, de origen purépecha. No se pueden considerar nahuatlismos ni híbridos español-náhuatl aguanchi, aguachinarse y aguachinoso 'aguado', registrados por Santamaría (1959) y Malaret (1946); tampoco cubiche, forma despectiva para hablar de un cubano, usado en las Antillas, y culichiche 'mequetrefe', también despectivo en Cuba según Malaret. El resto del vocabulario con terminación -che en este diccionario tiene diferentes procedencias: $a$ ) por evolución regular del latín al español (noche, leche, alache, etc.); b) del árabe (azabache, azache, zafariche, palmiche, etc.); $c$ ) de lenguas romance (pistache, romanche, birloche, fetiche, etc.); d) de otras lenguas (derviche, ceviche, tehuelche, soroche, etcétera).

Llaman la atención algunos vocablos que, como en los casos de cubichey culichiche, significan objetos dignos de burla, desprecio, etc., como caldibache 'calducho', cachivache, tiliche, bochinche, pichiruche 'persona insignificante' en Bolivia y Chile, según el Diccionario de la lengua española de la Real Academia.

30 Tal dificultad también pone en entredicho la supuesta etimología coca del vocablo mariachi, aducida por Dávila Garibi (sin que quiera decir que la etimología popular, que atribuye al francés mariage, tenga algún viso de verosimilitud). JáUREGUI (2001) sostiene que "Dávila Garibi nunca presentó documento alguno que permitiera comprobar su hipótesis acerca del origen del mariachi en Cocula, Jalisco, y de la etimología de la palabra mariachi a partir de la lengua coca" (p. 41; relacionado con ello, cf., además, Jáuregui 2007, p. 191, p.e.). Sin embargo, todo parece indicar que mariachi proviene de alguna de las lenguas del noroeste, del ópata, del yaqui o particularmente del cora, aunque tampoco hay investigaciones que permitan elaborar una hipótesis al respecto. Sólo se ha registrado la voz, primero, como topónimo en Nayarit, y luego, en un proceso semántico que va de un fandango a una tarima, a unos músicos. Dice Jáuregui (2012): "La famosa «carta de Rosamorada» de 1852 incluye el testimonio de que en la región costanera del actual Nayarit se denominaba a los fandangos -bailes populares al aire libre con borrachera- con el término «mariachis». La primera vez que el grupo musical aparece vinculado con el término «mariache» se encuentra en un testimonio de 1859, referente al pueblo de Tlalchapa, en el estado de Guerrero. En una crónica periodística de 1874 sobre Coalcomán, Michoacán, se designa por primera vez como «mariachi» a la música que ejecutan los grupos cordófonos del occidente mexicano. En 1892, otra vez en Santiago Ixcuintla, se denomina «mariache» a la tarima -el tambor de pie- sobre la que se zapatean sones y jarabes" (p. 224). 
Si bien es posible la hipótesis de Alatorre acerca de una hibridación español-náhuatl en la formación de esos diez adjetivos que significan "vicios infantiles", su falta de registros antiguos; la imposibilidad de saber si durante los dos siglos en que el náhuatl se manifestaba constantemente en el hablar de mestizos y criollos, había la probabilidad de construir adjetivos híbridos como los que imaginaba Alatorre; la dificultad para discernir cuál habría podido ser el radical español al que se añadiría -tzin, así como el automatismo de la " $i$ - de enlace" permiten ponerla en cuestión ${ }^{31}$ y considerar por el contrario que, como decía Lope Blanch, "no resultaría demasiado arriesgado suponer que la -ch- pueda tener, en la terminación de ciertas palabras, una fuerza (vis litterarum) -o vis sonorum, como precisó Alatorre la hipótesis de Lope Blanch (n. 13)- o resonancia claramente despectiva" (p. 633). Según las conclusiones a las que llega Lope Blanch, por su parte, un sufijo -i(n)che "no es de raigambre castiza", lo que supongo quiere decir que no se documenta en la evolución regular del español, aunque haya dado lugar a la formación de varios vocablos dispersos por el mundo hispánico, en donde el náhuatl no habrá podido tener influencia. Dice Lope Blanch: "La presencia de palabras terminadas en -i(n)che en otros países hispanohablantes libres de toda posible influencia nahua -palabras en que el contenido despectivo es evidente- no abona precisamente la idea de un origen azteca para esa terminación" (p. 633), lo que lo lleva a afirmar que los vocablos considerados por Alatorre serán mexicanismos, pero no híbridos español-náhuatl, aunque podría haber influencia indirecta del náhuatl, debido a la cantidad de voces que tienen esa terminación.

Los adjetivos considerados por Alatorre son afectivos, pero tienen un matiz despectivo, así como también los diminutivos tienen matices afectivos y despectivos. En español de México a los niños se les llama cariñosamente escuincles < itzcuintli, nombre del perro aborigen mexicano y chilpayates $^{32}$. Quizá chamaco y chamagoso tengan origen amerindio, aunque no se pueda encontrar ${ }^{33}$. En muchas lenguas, los diminutivos construyen vocablos reverenciales, afectivos y despectivos, así como ciertos sonidos, particularmente [i], dan lugar a la significación diminutiva y afectiva, como en español chiquito, bonito, finito,

31 El mismo AlatorRE observa: "las pilmamas bilingües hubieran podido decir por ejemplo llorontzin, llorotzin. Por qué «prefirieron» llor-i-tzin, imposible saberlo. - ¿Y cómo explicar que se diga lloriche y nunca llorinche, que se diga güerinche y nunca güeriche, que no se diga cantiche sino cantaliche, y que alternen pidiche y pidinche?" (p. 7, n. 11).

32 Cabrera 1974 explica su etimología tzipitl 'niño enfermo' + ayatl 'manta para llevarlo' o chiltic 'colorado' + payatl 'gusanillo velloso'. Ambas parecen muy improbables. De tzipitl viene chípil: "que está triste o melancólico, sobre todo las mujeres cuando están embarazadas o los niños cuando su madre está encinta” (DEM, s.v.).

33 López Austin considera muy improbable la etimología propuesta de chamahua 'crecer un niño'. 
tontito; en inglés tiny, slim, bit, slip; en italiano piccolo, piccino, ragazzino, finestrino, etc. También construyen hipocorísticos en español (generalmente con ortografía anglicizada) y en inglés: Mari, Leti, Pati, Lilly, Jimmy, Charly, Johnny, etc. El sonido [č] desempeña la misma función en español: Meche, Chucho, Nacho, Güicho, Lucha, Pancho, Licha, Chole $\mathrm{y}$, como señala Lope Blanch, se presta a formaciones afectivas y juguetonas como pechocho 'precioso', cochita 'cosita', bechito 'besito', panchita 'pancita', especialmente en la materlalia o manera de hablar a los niños, así como en de tocho morocho 'de todo' o iqué chabocha la chevecha que che chube a la cabecha! ${ }^{34}$.

Esos valores expresivos de fonemas como /i/ y / $\hat{c} /$ que no son "caprichosos", como los juzga Santamaría y lo relata Lope Blanch, sino que valen vis sonorum - revelan, por el contrario, la existencia de un mecanismo que se manifiesta en todas las lenguas: el fonosimbolismo, un fenómeno notado desde mucho tiempo atrás por la estilística, como en el caso más citado de Luis de Góngora: "infame turba de nocturnas aves", en la Fábula de Polifemo y Galatea, en donde es, sobre todo, el fonema $/ \mathrm{u} /$ el que resalta la oscuridad de la caverna de Polifemo, poblada de murciélagos. Recientemente, el neurólogo V.S. Ramachandran (2012) ha venido señalando que ese fenómeno, ya reconocido mucho tiempo atrás, corresponde a una serie de conexiones neuronales que tiene efectos sinestésicos, es decir, que la organización cerebral, sobre todo en los lóbulos temporales inferiores, permite el "cruce" de percepciones provenientes de diferentes órganos, como los de la vista y el oído. Esas íes o esas ches serían casos de relación entre lo pequeño y el sonido [u] con lo oscuro. Lo que permite tales fenómenos sinestésicos, propone Ramachandran, es la existencia de "células espejo", en realidad circuitos neuronales especiales -descubiertos por un equipo de neurofisiólogos italianos, presidido por Giacomo Rizzolatti-, propios del ser humano, aunque con presencia más limitada en otros animales, como los orangutanes, que llevan al ser humano a la imitación de lo que percibe: movimientos, sonidos, figuras, colores. Así, el sonido de [ĉc], africado y sordo, se prestaría a la expresión sonora de lo que se dice en la intimidad y murmurando: muy adecuado para el apapacho y el chiqueo infantiles, mediante esas versiones, también universales, del hablar a los niños llamadas materlalia, Lallwörter o motherese.

Yakov Malkiel (1990), quien fue un decidido propugnador del papel del fonosimbolismo en la formación y la evolución de las palabras, sabía a qué se enfrentaba cuando aducía explicaciones fonosimbólicas a algunos de los vocablos que caían bajo su observación.

34 Incluso esa che está en el origen de la voz pachuco, formada juguetonamente para nombrar a los mexicanos de El Paso - [el pacho]- que se extendieron por el suroeste de Estados Unidos de América desde finales de 1930 y durante la década de 1940. Véase LARA 1992. 
Según afirmaba, el predominio del positivismo característico de la lingüística heredera de los Junggrammatiker, empeñada en el descubrimiento de procesos regulares de evolución de los signos lingüísticos, logró marginar el papel del fonosimbolismo en la historia de las palabras. "In that climate of opinion, onomatopoeia and such fragments of children's language as lent themselves to eventual transfer to the language of adults, the celebrated Lallwörter, came last, sometimes relegated to apologetic footnotes, by way of marginal afterthought" (p. 10). Entre los muchos casos que ofrece Malkiel, se pueden citar chinche < esp. ant. cimze < lat. cimex y chiflar y chillar < lat. sïfiläre, en donde el fonema $/ \hat{c} /$ sustituye "caprichosamente" a $/ \theta /$ o a $/ \mathrm{s} /$ respectivamente. Para todos los casos examinados, tanto los supuestos híbridos español-náhuatl, como los que se registran en otras regiones del mundo hispánico, se puede proponer la hipótesis alternativa de que se trata de casos de fonosimbolismo del fonema / $\hat{c}$ / en español. A diferencia de la hipótesis de Alatorre, ad hoc para los diez adjetivos del español jalisciense, todos los casos señalados ${ }^{35}$, con excepción de los que revelan evolución regular del español, así como de los provenientes de otras lenguas (árabe, italiano, quechua, etc.) se pueden explicar como resultado del fenómeno del fonosimbolismo. Como efecto de ese mismo fenómeno, pero paradójicamente, voces como tencuache, pachiche, tololoche y cuatache o cuatacho serán híbridos, sí, pero de raíz nahua y sufijo fonosimbólico español, lo que corresponde a la adopción común de raíces nahuas en español de México.

\section{REFERENCIAS}

ACuña, René (ed.) 1982-1988. Relaciones geográficas del siglo XVI, Universidad Nacional Autónoma de México, México, 10 ts. (Serie Antropológica, 65).

Alatorre, Antonio 2001. "Sobre americanismos en general y mexicanismos en especial”, Nueva Revista de Filología Hispánica, 49, pp. 1-51.

Bosque, Ignacio 1987. Diccionario inverso de la lengua española, Gredos, Madrid.

Boyd-Bowman, Peter 1960. El habla de Guanajuato, Universidad Nacional Autónoma de México, México.

Cabrera, Luis 1974. Diccionario de aztequismos, Oasis, México.

CAMPbell, Lyle 1997. American Indian languages. The historical linguistics of Native America, Oxford University Press, Oxford. (Oxford Studies in Anthropological Linguistics, 4).

Corominas, Joan y José Antonio Pascual 1991. Diccionario crítico etimológico castellano e hispánico, Gredos, Madrid.

Cortés y Zedeño, Gerónimo Thomás de AQuino 1967 [1765]. Arte, vocabulario, y confessionario en idioma mexicano, como se usa en el Obispado de Guadalaxara. Ed. facsimilar de Edmundo Aviña Levy, Guadalajara, Jalisco.

35 Incluso, destaco, tencuache, jolinche y barbinche. El primero con raíz nahua pero sufijo despectivo; los otros con raíz española y el mismo sufijo. 
Covarrubias, Gaspar de 1986 [1580]. Relación de las minas de Temazcaltepeque, en Relaciones geográficas del siglo XV: México. Ed. R. Acuña, Universidad Nacional Autónoma de México, México, vol. 7, t. 2, pp. 135-154. (Serie Antropológica, 65).

Dávila Garibi, José Ignacio 1935. "Recopilación de datos acerca del idioma coca", Investigaciones Lingüisticas, 3, pp. 248-302.

Dávila Garibi, José Ignacio 1945. Los idiomas nativos de Jalisco y el problema de filiación de los ya desaparecidos, Impr. Manuel León Sánchez, México.

DEM: Diccionario del español de México, http:/ / dem.colmex.mx, El Colegio de México.

Díaz del Castillo, Bernal 2014 [1632]. Historia verdadera de la conquista de la Nueva España. Ed. Guillermo Serés, Academia Mexicana de la Lengua, México.

GuerRA, FRAY JuAN DE 1900 [1692]. Arte de la lengua mexicana. Que fue usual entre los indios del obispado de Guadalajara y de parte de los de Durango y Michoacán (1692). Prol. Alberto Santoscoy, Guadalajara, Jalisco.

JÁUREGUI, JESÚs 2001. "Una subtradición mariachera nayarita: la de Xalisco", en De Occidente es el mariache y de México... Revista de una tradición. Ed. Álvaro Ochoa Serrano, El Colegio de Michoacán-Secretaría de Cultura del Estado de Jalisco, Zamora, pp. 33-62.

Jáuregui, Jesús 2007. El mariachi, símbolo musical de México, Instituto Nacional de Antropología e Historia, México.

Jáuregui, Jesús 2012. "El mariachi, símbolo musical de México", Música Oral del Sur, 9, pp. 209-240.

LARA, Luis FERnANDo 1992. "Para la historia lingüística del pachuco", Anuario de Letras, 30, pp. 75-88.

LARA, Luis Fernando 2008. "Para la historia de la expansión del español por México en el siglo Xvi”, Nueva Revista de Filología Hispánica, 56, 2, pp. 297-362.

Lope Blanch, Juan M. 1992. "Mex. -che, -i(n)che ¿nahuatlismo?”, Nueva Revista de Filología Hispánica, 40, pp. 623-636.

López Austin, Alfredo 1996. Los mitos del tlacuache. Caminos de la mitología mesoamericana, $3^{\text {a }}$ ed., Universidad Nacional Autónoma de México, México.

Malaret, Augusto 1946. Diccionario de americanismos, Emecé, Buenos Aires.

Malkiel, Yakov 1990. Diachronic problems in phonosymbolism. Edita and inedita, 19791988, t. 1, John Benjamins, Amsterdam.

Molina, Alonso de 1576. Arte de la lengua mexicana, $2^{\mathrm{a}}$ ed., Pedro Ocharte, México.

Molina, Alonso de 2013 [1555]. Vocabulario en lengua castellana mexicana, mexicana castellana, Porrúa, México.

Montemayor, Carlos (coord.) 2007. Diccionario del náhuatl en el español de México, Universidad Nacional Autónoma de México, México.

Orozco y Berra, Manuel 1864. Geografía de las lenguas y carta etnográfica de México: precedidas de un ensayo de clasificación de las mismas lenguas y de apuntes para las inmigraciones de las tribus, Imprenta de Andrade y Escalante, México.

RAMACHANDRAN, VilayanUR S. 2012. The tell-tale brain: Unlocking the mystery of human nature, Windmill Books, London.

Real Academia Española 2014. Diccionario de la lengua española, Espasa, Madrid.

Robelo, Cecilio A. 1940. Diccionario de aztequismos, Eds. Fuente Cultural, México.

Santamaría, Francisco J. 1959. Diccionario de mejicanismos, Porrúa, México.

Swadesh, Mauricio 1966. Los mil elementos del mexicano clásico: base analítica de la lengua nahua, Universidad Nacional Autónoma de México, México. 